\title{
DETERMINATION OF SOIL HYDRAULIC PROPERTIES IN A PART OF HINDON RIVER CATCHMENT USING SOILPROP SOFTWARE
}

\author{
C. P. Kumar ${ }^{1}$ and Sanjay Mittal ${ }^{2}$
}

\begin{abstract}
Mathematical models of hydrologic and agricultural systems require knowledge of the relationships between soil moisture content $(\theta)$, soil water pressure (h) and unsaturated hydraulic conductivity (K). To model the retention and movement of water and chemicals in the unsaturated zone, it is necessary to know the relationships between soil water pressure, water content and hydraulic conductivity. It is often convenient to represent these functions by means of relatively simple parametric expressions. The problem of characterizing the soil hydraulic properties then reduces to estimating parameters of the appropriate constitutive model. A number of models for water retention function and unsaturated hydraulic conductivity are well reported in literature, the most popular being van Genuchten model and BrooksCorey model. In general, the van Genuchten model matches experimental data more satisfactorily than Brooks-Corey model. However, the functional form of van Genuchten model is complicated and limits its usefulness for large number of analytical solutions available for infiltration and drainage problems. On the other hand, Brooks-Corey model yields conductivity and water retention functions that are easy to manipulate mathematically.
\end{abstract}

For this study, 27 soil samples were collected from various locations as well as depths in different villages, namely Aurangabad, Kamalpur, Budhakhera, Gagalheri, Dudhil Bukhara in the upstream part of Hindon river catchment and laboratory investigations were carried out to determine bulk density and grain size distribution. Using these data as input to the SOILPROP software, van Genuchten and Brooks-Corey parameters ( $\alpha$ and $\mathrm{n} \& \mathrm{~h}_{\mathrm{d}}$ and $\lambda$ ) were determined to derive the retention characteristic and unsaturated hydraulic conductivity. The values of $\alpha$ and $\mathrm{n}$ (van Genuchten parameters) were found to vary from 0.00004 to 0.00078 and 1.19 to 1.65 respectively. The values of $h_{d}$ and $\lambda$ (Brooks-Corey parameters) were found to vary from 860 to $20200 \mathrm{~cm}$ and 0.189 to 0.538 respectively. These results (as necessary input for unsaturated zone modeling) will be helpful for prediction of soil moisture flow and groundwater recharge in the Hindon river catchment.

KEY WORDS: Bulk density, Grain size analysis, unsaturated zone, van Genuchten model, Brooks-Corey model, SOILPROP software.

\section{INTRODUCTION}

The water movement in the unsaturated zone, together with its water holding capacity is very important for assessing the water demand of the vegetation, as well as for recharge of the ground water storage. A fair description of the flow in the unsaturated zone is also crucial for prediction of the movement of pollutants into ground water aquifers.

For analytical studies on soil moisture regime, critical review and accurate assessment of different controlling factors is necessary. The controlling soil factors for movement of soil moisture include soil matric potential and water content relationship, hydraulic conductivity and water content relationship, saturated hydraulic conductivity and effective porosity. Saturated and unsaturated hydraulic conductivity is related to the degree of resistance from soil particles when water flows through soil pores. Unsaturated hydraulic conductivity is affected markedly by the volumetric water content of soil. Direct measurement of unsaturated hydraulic conductivity is difficult and it can be indirectly evaluated through the soil moisture characteristic curve.

\section{Scientist 'F' 2. Senior Research Assistant}

National Institute of Hydrology, Roorkee - 247667 (Uttarakhand) 
The relation between matric potential and volumetric water content in a soil is termed as the soil moisture characteristic curve. The differences among soil moisture characteristic curves for different soils are attributed primarily to the differences in pore size distribution among soils. These curves are sensitive to the change in bulk densities and disturbances of soil structures. In addition, the curves generally show hysteresis according to the degree of wetting or drying of soils. These curves are useful to understand the amount of water that is available to plants, the water that can be taken up by the soil before percolation starts and the amount of water that must be used for irrigation (Michael, 1986).

In this paper, 27 disturbed soil samples were collected from various locations as well as depths in different villages, namely Aurangabad, Kamalpur, Budhakhera, Gagalheri, Dudhil Bukhara in the upstream part of Hindon river catchment. For these soil samples, bulk density was measured through Geopyc 1360 and grain size analysis was carried out by mechanical sieve analysis and Master Sizer-E system in the laboratory. These soil parameters were used to derive van Genuchten and Brooks-Corey parameters using the SOILPROP software.

\section{VAN GENUCHTEN AND BROOKS-COREY MODELS}

The modeling of water movement through soil typically requires the functional representation of soil hydraulic properties, such as soil moisture retention curve and the unsaturated hydraulic conductivity. There are two commonly used models i.e. Brooks and Corey (1964) and van Genuchten (1980). In general, the van Genuchten (VG) model matches experimental data more satisfactorily than the model of Brooks and Corey (BC). However, the functional form of van Genuchten model is complicated and limits its usefulness for large number of analytical solutions available for infiltration and drainage problems. On the other hand, Brooks-Corey model yields conductivity and water retention functions that are easy to manipulate mathematically.

\section{van Genuchten Model}

For the van Genuchten model, the water retention function is given by

$$
\begin{array}{ll}
\left.\mathrm{S}_{\mathrm{e}}=\left[1+(\alpha \mathrm{h})^{\mathrm{n}}\right)\right]^{-\mathrm{m},} & \mathrm{h}>0 \\
\mathrm{~S}_{\mathrm{e}}=1 & \mathrm{~h} \leq 0
\end{array}
$$

where, $\alpha$ and $\mathrm{n}$ are VG model parameters, $\mathrm{m}=1-1 / \mathrm{n}, \mathrm{h}$ is the capillary pressure head (i.e. the difference between gas and water pressures expressed in equivalent height of water) and $\mathrm{S}_{\mathrm{e}}$ is the effective saturation defined by

$$
\begin{aligned}
& \mathrm{S}_{\mathrm{e}}=\left(\theta-\theta_{\mathrm{m}}\right) /\left(\theta_{\mathrm{s}}-\theta_{\mathrm{m}}\right) \\
& \mathrm{S}_{\mathrm{e}}=\left(\mathrm{S}-\mathrm{S}_{\mathrm{m}}\right) /\left(1-\mathrm{S}_{\mathrm{m}}\right)
\end{aligned}
$$

where, $\theta$ is the water content, $\theta_{\mathrm{s}}$ is the water content at zero capillary head, $\theta_{\mathrm{m}}$ is an apparent "irreducible" water content that occurs for large capillary heads, $S$ is the water saturation $\left(=\theta / \theta_{\mathrm{s}}\right)$ and $S_{m}$ is the irreducible water saturation $\left(=\theta_{\mathrm{m}} / \theta_{\mathrm{s}}\right)$.

The conductivity function is described by

$$
\mathrm{K}=\mathrm{K}_{\mathrm{s}} \mathrm{S}_{\mathrm{e}}{ }^{1 / 2}\left[1-\left(1-\mathrm{S}_{\mathrm{e}}{ }^{1 / \mathrm{m}}\right)^{\mathrm{m}}\right]^{2}
$$

$\mathrm{K}$ is hydraulic conductivity at a specified water saturation and $\mathrm{K}_{\mathrm{s}}$ is saturated hydraulic conductivity of the soil. 


\section{Brooks-Corey Model}

For the Brooks-Corey model, the soil water retention function, or capillary pressure function is represented by

$$
\begin{array}{ll}
\mathrm{S}_{\mathrm{e}}=\left(\mathrm{h}_{\mathrm{d}} / \mathrm{h}\right)^{\lambda}, & \mathrm{h}>\mathrm{h}_{\mathrm{d}} \\
\mathrm{S}_{\mathrm{e}}=1 & \mathrm{~h} \leq \mathrm{h}_{\mathrm{d}}
\end{array}
$$

where, $h_{d}$ and $\lambda$ are BC parameters referred to as the air entry head and pore size distribution index respectively

The hydraulic conductivity function corresponding to the $\mathrm{BC}$ retention function is represented by

$$
\mathrm{K}=\mathrm{K}_{\mathrm{s}} \mathrm{S}_{\mathrm{e}}^{(2+3 \lambda) / \lambda}
$$

Lenhard et al. (1989) discussed a method for converting a VG water retention model to an equivalent BC model. This conversion procedure is included in SOILPROP software. The conversion can be useful in cases where VG parameters are available but the water-transport models prefer a $\mathrm{BC}$ model. In addition, analytical formulae requiring integrals of the soil water diffusivity are better suited to the $\mathrm{BC}$ formulation. The model of Lenhard et al. (1989) for converting VG parameters into BC parameters works well when modeling infiltration into non-clayey soils (larger $\mathrm{n}$ values), but is inadequate for clayey soils (smaller $\mathrm{n}$ ). It is possible to obtain closer agreement between the two models, if conductivity in the BC model is multiplied by a scaling factor dependent on $\mathrm{n}$, which affects the saturated conductivity.

\section{SOILPROP SOFTWARE}

Soil hydraulic properties are macroscopic properties - that is, properties defined at a scale much larger than the pore scale. However, these properties depend very much on the characteristics of the soil at the pore scale and in particular on the pore size distribution. Since the pore size distribution is controlled to a large extent by the size distribution of the soil particles, hydraulic properties and thus the parameters in the $\mathrm{BC}$ and VG models, will vary with the particle size distribution of the soil in a way that is more or less predictable.

SOILPROP is an interactive program for estimating soil hydraulic properties $\left(K_{s}, \alpha, n, h_{d}, \lambda\right)$ from particle size distribution (PSD) and bulk density data of the soil. SOILPROP is based on the premise that the soil water retention function $S(h)$ or $\theta(h)$, reflects an underlying pore size distribution which can be deduced from the particle size distribution (Arya and Paris, 1981). Since soil textural information is more easily obtained than static or dynamic hydraulic data, the use of SOILPROP software is useful where soil retention characteristic and saturated hydraulic conductivity data are not available.

\section{STUDY AREA}

The study area lies in the upper part of Hindon basin, bounded between latitude $29^{\circ} 55^{\prime}$ and $30^{\circ} 6^{\prime}$ and longitude $77^{\circ} 35^{\prime}$ and $77^{\circ} 46^{\prime}$ (Figure 1). The area is located within Saharanpur district of Uttar Pradesh (India) and included in the Survey of India topographic sheets 53 F/12, 53 F/16, 53 G/9 and 53 G/13 in the scale of 1:50,000. The investigated area covers a reach of around $24 \mathrm{~km}$ along the Hindon river in its upstream reach. The study is confined to a stretch of Hindon river between Aurangabad and Dudhil Bukhara villages.

The climate in the Hindon basin is moderate to subtropical monsoon type. The average annual monsoon rainfall in Saharanpur town is $886 \mathrm{~mm}$ and the temperature variation is from $8^{0} \mathrm{C}$ in winter to $40^{\circ} \mathrm{C}$ in summer. The drainage of the area comprises of the Hindon river, which is an ephemeral river flowing towards south. The river finally meets the Yamuna river (a tributary to the river Ganges near Ghaziabad (latitude $28^{0} 28^{\prime} \mathrm{N}$ ) outside the study area. 
The soil is alluvial type deposited by Hindon river system. Lithologically, it mainly consists of clay, silt and fine to coarse sand. The soils are very fertile for growing wheat, sugarcane and vegetables. However, along the sandy river course, fruit orchards are also common.

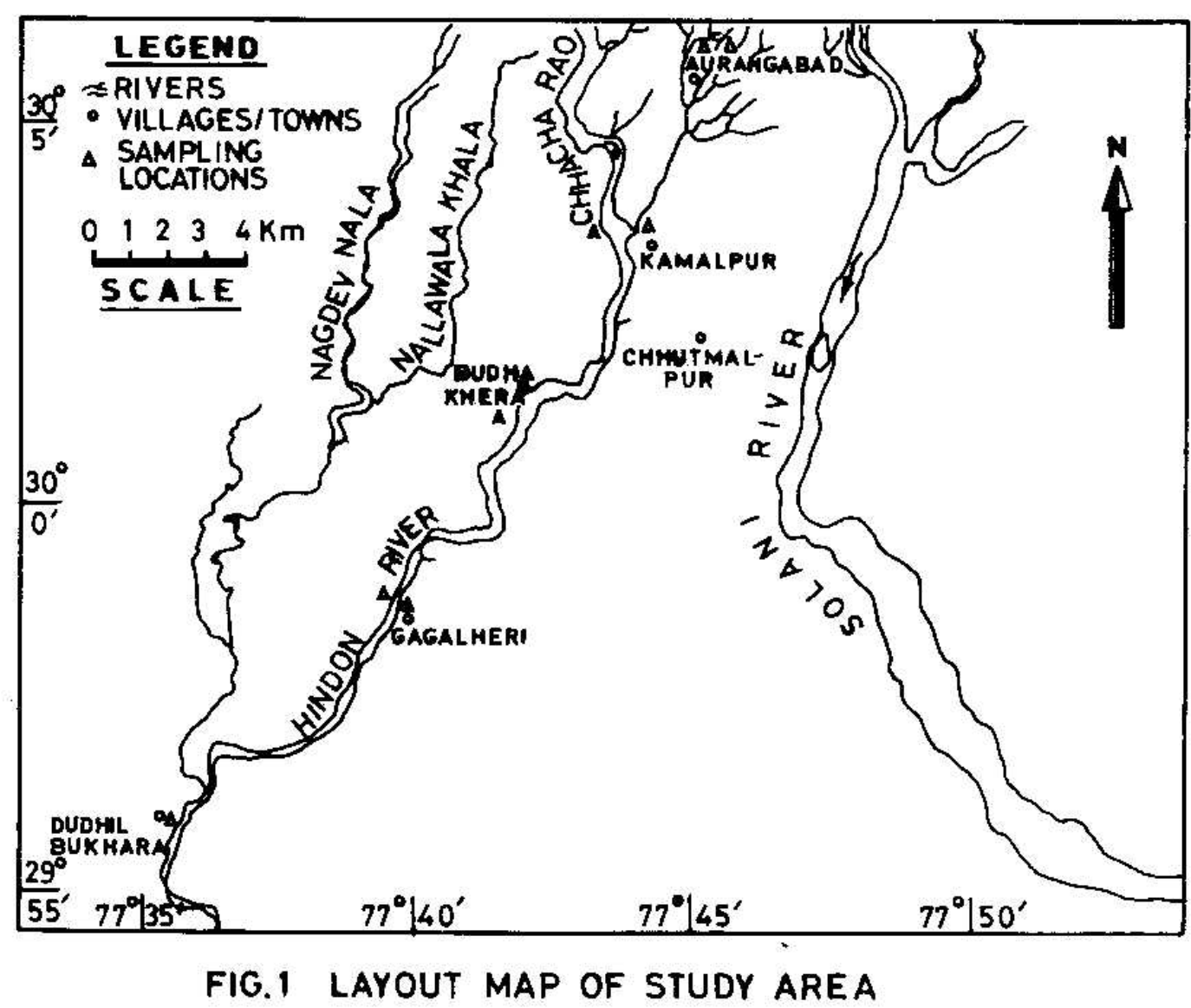

\section{METHODOLOGY}

A total of 27 soil samples were collected from various locations and depths in Aurangabad, Kamalpur, Budhakhera, Gagalheri and Dudhil Bukhara villages, which comprised around $24 \mathrm{~km}$ reach, upstream part of Hindon river. Disturbed soil samples were collected from these sites after clearing the vegetation and roots from the top surface. These soil samples were used to measure grain size distribution and bulk density in the laboratory.

\section{Measurement of particle size distribution}

A set of ASTM sieves (i.e. 4, 10, 14, 20, 40, 60, 70, 200 nos.) were used for this analysis. To determine grain size distribution, oven dried soil sample weighing $500 \mathrm{gm}$ is washed through the sieve number 200 (i.e.75 micron). The portion of soil particles retained on sieve (coarse grain, bigger than 75 micron) is subjected to mechanical sieve analysis and the particle passing through the sieve (fine grain, smaller than 75 micron) is subjected to Master Sizer analysis. In sieve analysis, the portion retained on each sieve is collected and weighed. The percentage of soil sample retained on each sieve on the basis of total weight of soil sample and the percentage of weight passing through each sieve is calculated (Bowles,1986). The fraction of the soil, which is finer than 75 micron size, is used for Master Sizer-E system analysis. The 
Master Sizer-E system works on the principle of laser ensemble light scattering. They fall into the category of non-imaging optical systems due to the fact that sizing is accomplished without forming an image of the particle onto a detector.

The results of coarse grain analysis and fine grain analysis were blended. The results obtained from Master Sizer-E system were volumetric and were converted into gravimetric by multiplying with bulk density of the soil. The results of the fine grain analysis were converted into the percentage of the total soil samples. The soil texture (percentage of sand, silt and clay) was thus obtained for each soil sample.

\section{Measurement of bulk density}

Bulk density (T.A.P. Transverse Axial Pressure density) was measured by GeoPyc 1360 for all the soil samples. Geopyc 1360 Pycnometer measures the bulk volume and calculates the bulk density of granular and powdered samples under a wide range of compaction conditions. The traditional method for determining bulk volume involves tapping or vibrating the sample within a graduated cylinder, measuring the sample's density at a single packing or consolidation condition. The GeoPyc determines the bulk density of packed or consolidated samples with the degree of packing accurately quantified.

\section{Use of SOILPROP software}

One common approach is to take $\mathrm{S}(\mathrm{h})$ measurements from soil cores and fit them to the desired soil-water retention model (1) or (4). Once the retention function is estimated, the conductivity relation, $\mathrm{K}(\mathrm{S})$ can be evaluated from equation (3) or (5), if the saturated conductivity, $\mathrm{K}_{\mathrm{s}}$ is known. Methods have been proposed for computing soil-water retention relations from PSD data using regression equations or via models with quasi-physical bases. Methods for estimating saturated conductivity, $\mathrm{K}_{\mathrm{s}}$, from PSD data are generally based on the use of Kozeny-Carman equation, or variations thereof, which involve a relationship between saturated conductivity, porosity and some representative particle diameter. The procedure implemented in SOILPROP is based on the method of Mishra et al. (1989).

Due to practical problems with automatic fitting of the BC model to $\theta(\mathrm{h})$ data, SOILPROP software first fits the VG model to $\theta(\mathrm{h})$ data to estimate $\alpha, \mathrm{n}$ and $\theta_{\mathrm{r}}$ (residual moisture content) and then converts these to "equivalent" $\mathrm{BC}$ model parameters. The VG parameters $\alpha$ and $\mathrm{n}$ are internally converted to the $\mathrm{BC}$ model parameters $h_{d}$ and $\lambda$ by specifying the effective saturation at which the $B C$ and VG $\theta(h)$ curves are forced to cross. The estimation of soil hydraulic properties from PSD data offers substantial savings in experimental effort over more direct calibration methods. Moreover, results provided by the SOILPROP software are of satisfactory precision for many purposes.

However, knowledge of the accuracy of parameter estimates is important in order to properly assess the impact on predictions which are to be made. Procedures for performing such error analyses have been presented by Mishra and Parker (1989). It was found that $\mathrm{S}_{\mathrm{e}}(\mathrm{h})$ and $\mathrm{K}(\theta)$ from particle size distribution data provides results of satisfactory precision for many purposes. However, estimation of $\mathrm{K}_{\mathrm{s}}$ is subject to large uncertainty. Therefore, direct measurement of $\mathrm{K}_{\mathrm{s}}$ may be necessary to obtain satisfactory precision in prediction of field behaviour.

The SOILPROP software was used to determine the parameters of van Genuchten and Brooks-Corey models for all the soil samples collected. The input data required to estimate the parameters of VG model and $\mathrm{BC}$ model through SOILPROP are particle size distribution and bulk density. The output obtained through SOILPROP are $\alpha, n$ and $R^{\wedge} 2$ (the coefficient of determination) for VG model and $h_{d}$ and $\lambda$ for $B C$ model.

\section{RESULTS AND DISCUSSION}

All the 27 disturbed soil samples collected from different locations and depths in the study area were analyzed in the laboratory. Table 1 shows the textural classification of soils at different locations in the study area. 
Using the grain size and bulk density data for each soil sample (27 nos.), the parameters of van Genuchten and Brooks-Corey models were obtained by using the SOILPROP software, as presented in Table 1. As typical examples, retention curve and relative permeability curve at sites A12 (silty loam), D12 (loamy sand) and G11 (silt), as obtained through van Genuchten and Brooks-Corey models, are shown in Figures 2,3 and 4 respectively.

TABLE 1 - PARAMETERS OF VAN GENUCHTEN AND BROOKS-COREY MODELS

\begin{tabular}{|c|c|c|c|c|c|c|c|c|c|c|c|c|}
\hline \multirow{2}{*}{ S.N } & \multirow{2}{*}{ Location } & \multicolumn{6}{|c|}{ Laboratory Measurement } & \multicolumn{3}{|c|}{$\begin{array}{c}\text { Van Genucten } \\
\text { Parameter }\end{array}$} & \multicolumn{2}{|c|}{$\begin{array}{c}\text { Brooks Corey } \\
\text { Parameter }\end{array}$} \\
\hline & & $\begin{array}{c}\text { Bulk } \\
\text { Density } \\
\text { (gm/cc) }\end{array}$ & $\begin{array}{l}\% \text { of } \\
\text { Gravel }\end{array}$ & $\begin{array}{l}\% \text { of } \\
\text { Sand }\end{array}$ & $\%$ of Silt & $\begin{array}{l}\% \text { of } \\
\text { Clay }\end{array}$ & $\begin{array}{c}\mathrm{K}_{\mathrm{s}} \\
(\mathrm{cm} / \text { day })\end{array}$ & $\alpha$ & $\mathrm{n}$ & $\mathrm{R}^{\wedge} 2$ & $\mathrm{~h}_{\mathrm{d}}(\mathrm{cm})$ & $\lambda$ \\
\hline 1 & A11 & 1.47 & 0.01 & 30.51 & 60.08 & 9.40 & 0.197 & 0.00012 & 1.21 & 0.9725 & 6900 & 0.206 \\
\hline 2 & A12 & 1.39 & 0.11 & 32.58 & 58.14 & 9.17 & 0.231 & 0.00015 & 1.20 & 0.9741 & 5550 & 0.199 \\
\hline 3 & A21 & 1.41 & 0.00 & 33.35 & 57.75 & 8.90 & 0.242 & 0.00015 & 1.20 & 0.9749 & 5370 & 0.200 \\
\hline 4 & A22 & 1.48 & 0.02 & 32.28 & 58.61 & 9.09 & 0.214 & 0.00014 & 1.21 & 0.9739 & 6100 & 0.202 \\
\hline 5 & $\mathrm{~A} 23$ & 1.41 & 0.16 & 36.94 & 54.57 & 8.33 & 0.298 & 0.00020 & 1.20 & 0.9785 & 4240 & 0.194 \\
\hline 6 & A31 & 1.58 & 0.00 & 39.99 & 51.48 & 8.53 & 0.287 & 0.00019 & 1.19 & 0.9825 & 4400 & 0.189 \\
\hline 7 & $\mathrm{~A} 32$ & 1.45 & 0.00 & 32.47 & 58.83 & 8.70 & 0.233 & 0.00015 & 1.21 & 0.9737 & 5680 & 0.204 \\
\hline 8 & A33 & 1.45 & 0.00 & 45.48 & 47.96 & 6.56 & 0.556 & 0.00029 & 1.20 & 0.987 & 2880 & 0.201 \\
\hline 9 & A41 & 1.31 & 0.00 & 60.06 & 35.75 & 4.19 & 2.260 & 0.00055 & 1.25 & 0.9964 & 1410 & 0.241 \\
\hline 10 & A42 & 1.46 & 0.00 & 19.89 & 68.83 & 11.28 & 0.118 & 0.00004 & 1.29 & 0.9757 & 20200 & 0.280 \\
\hline 11 & A43 & 1.36 & 0.04 & 42.04 & 52.50 & 5.42 & 0.567 & 0.00030 & 1.21 & 0.982 & 2700 & 0.208 \\
\hline 12 & K11 & 1.57 & 0.33 & 98.23 & 1.38 & 0.06 & 18.100 & 0.00041 & 1.65 & 0.9936 & 1480 & 0.538 \\
\hline 13 & K13 & 1.59 & 1.69 & 96.69 & 1.55 & 0.07 & 18.300 & 0.00050 & 1.57 & 0.9933 & 1240 & 0.488 \\
\hline 14 & K21 & 1.54 & 0.00 & 88.70 & 10.77 & 0.53 & 12.300 & 0.00050 & 1.48 & 0.9973 & 1300 & 0.425 \\
\hline 15 & K23 & 1.67 & 0.37 & 97.01 & 2.52 & 0.10 & 15.700 & 0.00038 & 1.62 & 0.9946 & 1610 & 0.519 \\
\hline 16 & K31 & 1.30 & 0.42 & 75.60 & 23.10 & 0.88 & 7.910 & 0.00068 & 1.35 & 0.9984 & 1030 & 0.326 \\
\hline 17 & K61 & 1.56 & 0.00 & 86.00 & 13.29 & 0.71 & 10.700 & 0.00047 & 1.46 & 0.9978 & 1400 & 0.412 \\
\hline 18 & K62 & 1.53 & 0.00 & 91.05 & 8.41 & 0.54 & 13.700 & 0.00047 & 1.52 & 0.9968 & 1340 & 0.453 \\
\hline 19 & B12 & 1.40 & 0.00 & 94.54 & 5.16 & 0.30 & 17.900 & 0.00049 & 1.58 & 0.9957 & 1270 & 0.492 \\
\hline 20 & B13 & 1.51 & 0.00 & 92.55 & 7.11 & 0.34 & 14.900 & 0.00047 & 1.55 & 0.9964 & 1340 & 0.470 \\
\hline 21 & G11 & 1.53 & 1.91 & 16.36 & 75.89 & 5.84 & 0.202 & 0.00005 & 1.34 & 0.9713 & 13000 & 0.315 \\
\hline 22 & G12 & 1.47 & 2.00 & 22.27 & 70.59 & 5.14 & 0.278 & 0.00008 & 1.31 & 0.9667 & 9360 & 0.291 \\
\hline 23 & G13 & 1.53 & 0.00 & 81.73 & 17.17 & 1.10 & 8.920 & 0.00052 & 1.41 & 0.9984 & 1300 & 0.370 \\
\hline 24 & G21 & 1.46 & 0.10 & 98.31 & 1.49 & 0.10 & 19.500 & 0.00043 & 1.64 & 0.9941 & 1420 & 0.530 \\
\hline 25 & D11 & 1.11 & 0.00 & 47.35 & 50.03 & 2.62 & 1.240 & 0.00044 & 1.25 & 0.985 & 1790 & 0.238 \\
\hline 26 & D12 & 1.20 & 0.00 & 85.30 & 13.96 & 0.74 & 13.900 & 0.00078 & 1.40 & 0.9978 & 860 & 0.368 \\
\hline 27 & D14 & 1.32 & 0.00 & 95.82 & 3.96 & 0.22 & 20.000 & 0.00046 & 1.64 & 0.9948 & 1330 & 0.533 \\
\hline
\end{tabular}

From Table 1, it is observed that the values of $\alpha$ and $\mathrm{n}$ (van Genuchten parameters) were found to vary from 0.00004 to 0.00078 and 1.19 to 1.65 respectively. The coefficient of determination $\mathrm{R}^{\wedge} 2$ varies from 0.9667 to 0.9984 for VG model. The values of $h_{d}$ and $\lambda$ (Brooks-Corey parameters) were found to vary from 860 to $20200 \mathrm{~cm}$ and 0.189 to 0.538 respectively.

The variation of $\mathrm{n}$ (van Genuchten parameter) with $\mathrm{K}_{\mathrm{s}}$ (saturated hydraulic conductivity) in the study area is shown in Figure 5. It is observed that $\mathrm{n}$ lies within a limited range (1.2 to 1.7) with increase of saturated hydraulic conductivity. Similarly, the variation of $h_{d}$ (Brooks-Corey parameter) with $K_{s}$ (saturated hydraulic conductivity) is shown in Figure 6. Initially, with increase in $\mathrm{K}_{\mathrm{s}}$ from 0 to $2 \mathrm{~cm} /$ day, there is sharp decline in $h_{d}$ value, afterwards there is very gradual decrease in $h_{d}$ value. 


\section{Location A12 (Silty Loam)}
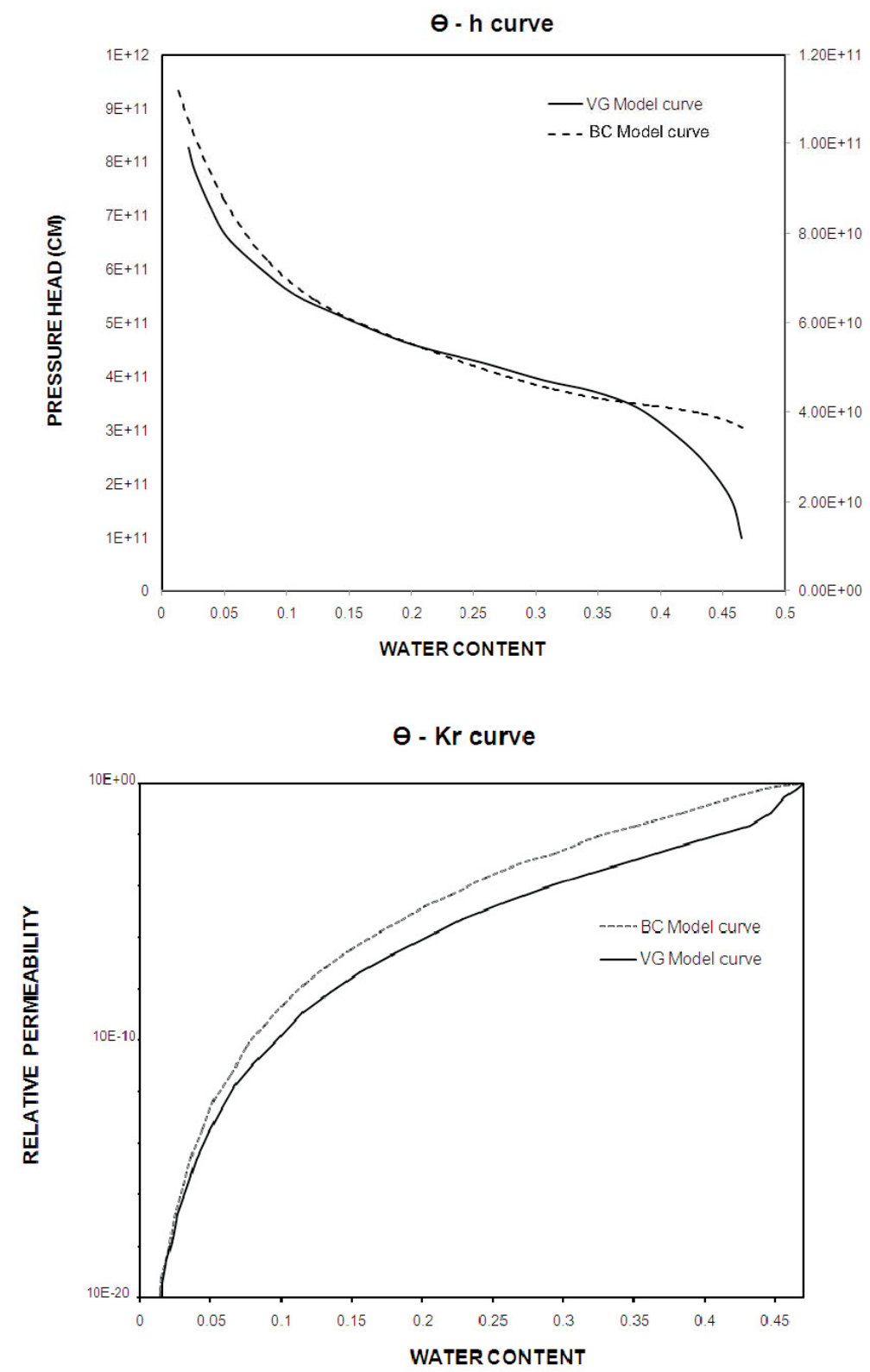

FIG. 2 RETENTION CURVE AND RELATIVE PERMEABILITY CURVE AT SITE A12 (SILTY LOAM) 


\section{Location D12 (Loamy Sand)}

$\boldsymbol{\theta}$ - h curve
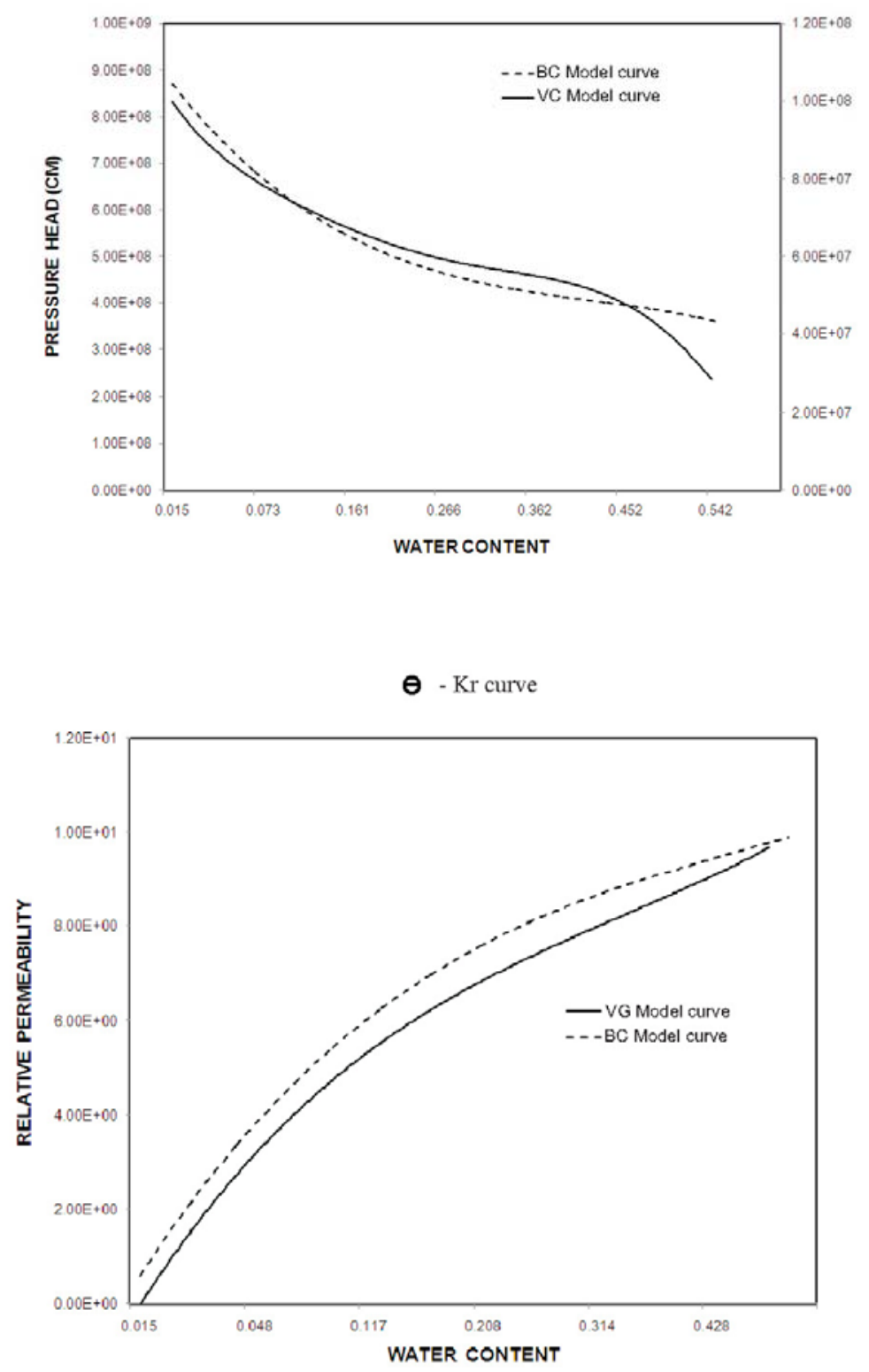

FIG. 3 RETENTION CURVE AND RELATIVE PERMEABILITY CURVE AT SITE D12 (LOAMY SAND) 


\section{Location G11 (Silt)}
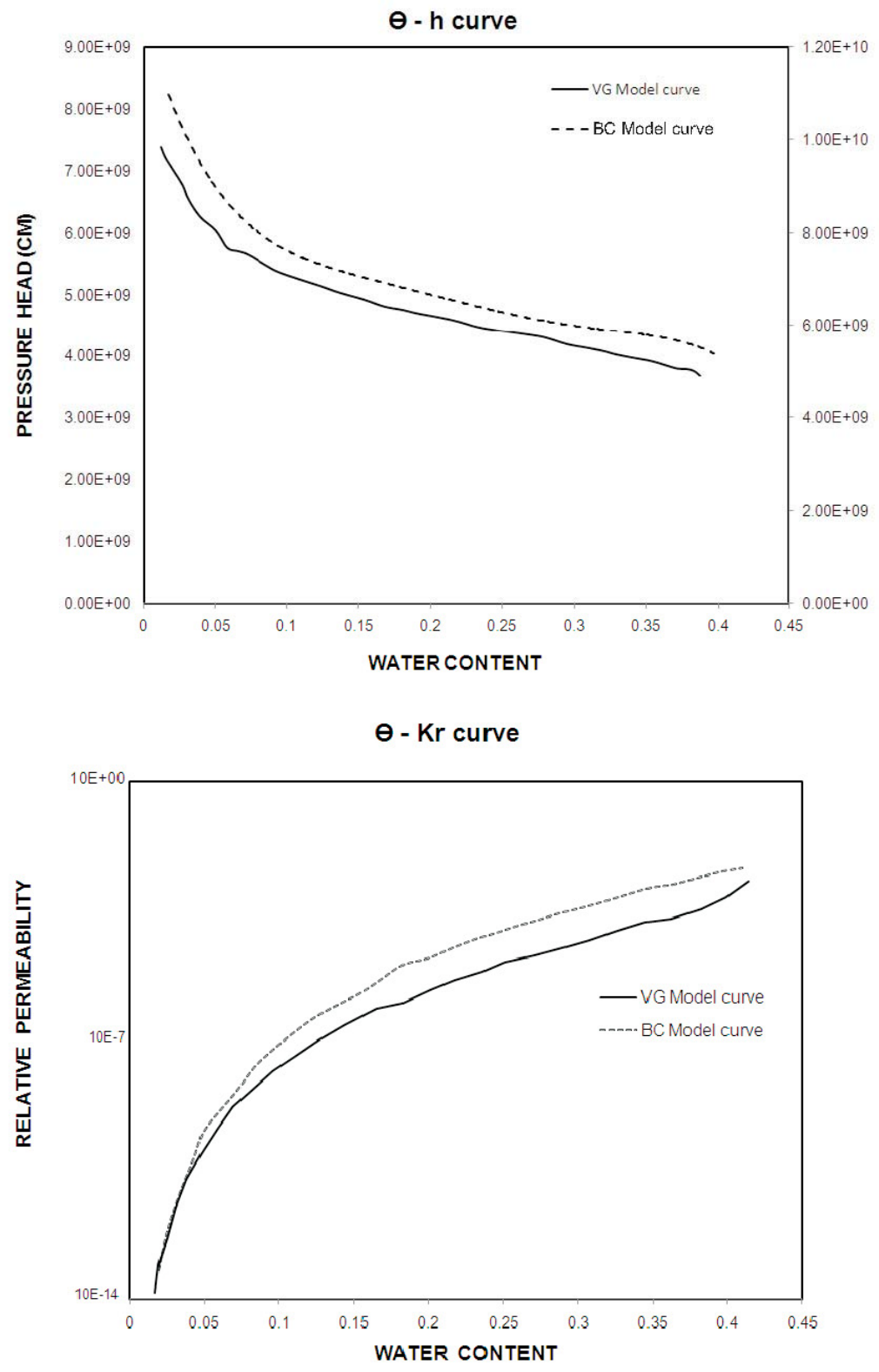

FIG. 4 RETENTION CURVE AND RELATIVE PERMEABILITY CURVE AT SITE G11 (SILT) 


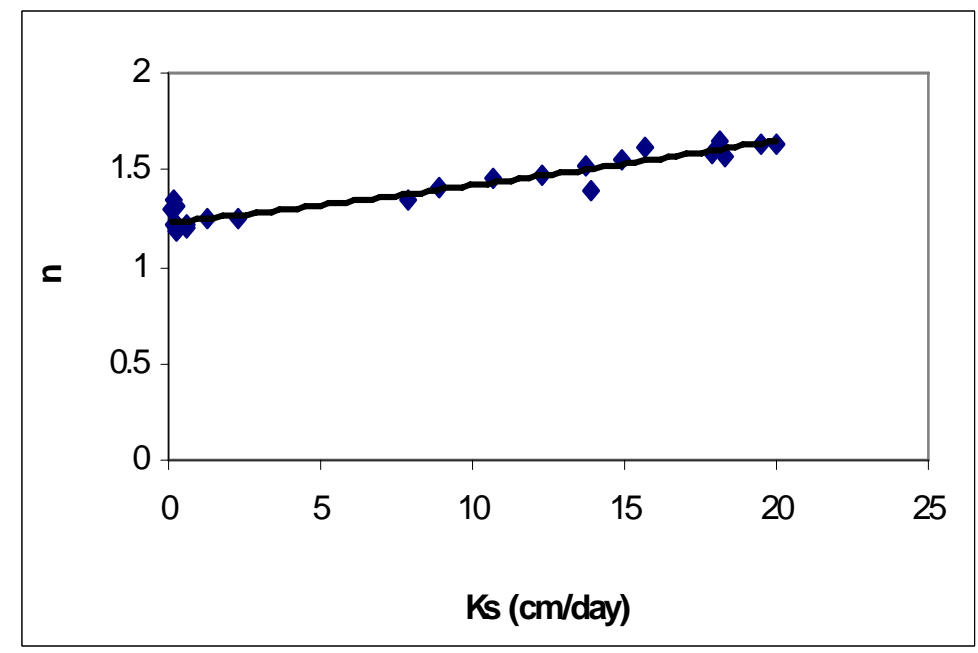

FIG. 5 VARIATION OF VAN GENUCHTEN PARAMETER (n) WITH SATURATED HYDRAULIC CONDUCTIVITY IN THE STUDY AREA

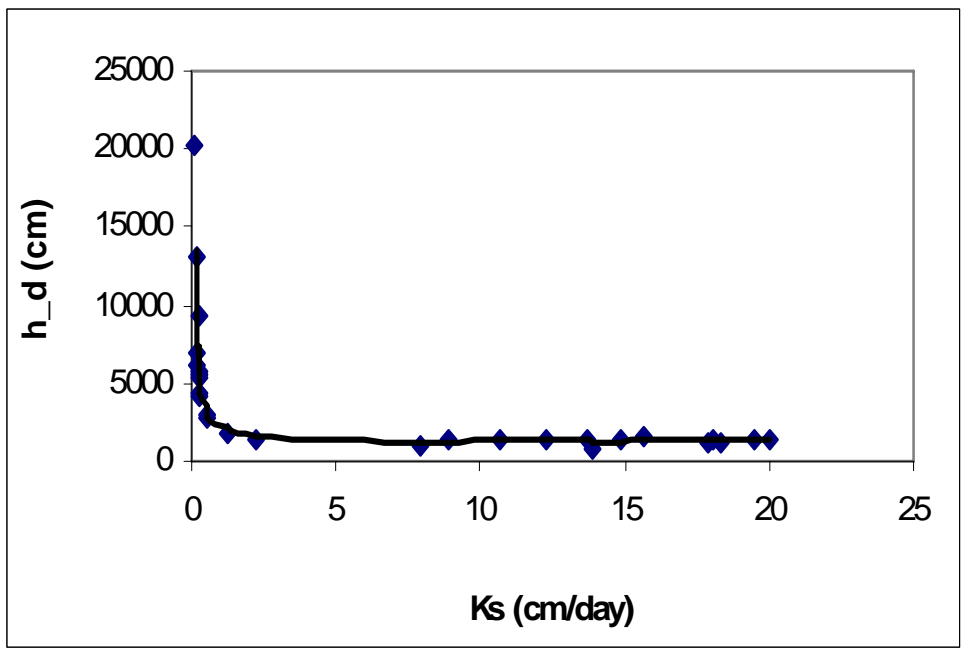

FIG. 6 VARIATION OF BROOKS-COREY PARAMETER WITH SATURATED HYDRAULIC CONDUCTIVITY IN THE STUDY AREA 


\section{CONCLUSION}

Using the SOILPROP software, parameters of van Genuchten model ( $\alpha$ and $n)$ and Brooks-Corey model $\left(h_{d}\right.$ and $\lambda$ ) were determined for different locations in upper part of Hindon river catchment in order to derive the soil moisture retention data and unsaturated hydraulic conductivity. The values of $\alpha$ and $n$ (van Genuchten parameters) were found to vary from 0.00004 to 0.00078 and 1.19 to 1.65 respectively. The values of $h_{d}$ and $\lambda$ (Brooks-Corey parameters) were found to vary from 860 to $20200 \mathrm{~cm}$ and 0.189 to 0.538 respectively. These results (as necessary input for unsaturated zone modeling) will be helpful for prediction of soil moisture flow and groundwater recharge in the Hindon river catchment.

\section{REFERENCES}

Arya, L. M. and Paris, J. F. (1981). "A physicoempirical model to predict soil moisture characteristics from particle size distribution and bulk density data". Soil Sci. Soc. Am. J., 45, 1023-1030.

Bowels, J.E. (1986). Engineering Properties of soils and their measurement, Third edition, McGraw Hill Book Company, Singapore.

Brooks, R. H., and Corey, A.T. (1964). "Hydraulic properties of porous media". Hydrology Paper No. 3, Colorado State Uni., Fort Collins, Colo.

Lenhard, R.J., Parker, J.C., and Mishra, S. (1989). "Of the correspondence between Brooks-Corey and van Genuchten models”. J. Irrig. and Drain. Engg., ASCE, 115(15), 744-751.

Michael, A. M. (1986). Irrigation-Theory and Practice, Vikas Publishing House Pvt., New Delhi.

Mishra, S. and Parker, J.C. (1989). "Effects of parameter uncertainty on predictions of unsaturated flow". J. Hydrol., 108, 19-33.

Mishra, S., Parker, J.C. and Singhal N. (1989). "Estimation of soil hydraulic properties and their uncertainty from particle size distribution data". J. Hydrol., 108, 1-18.

Soilprop Software User Guide (1993), Environmental Systems \& Technologies, Inc. , U.S.A.

van Genuchten, M.T. (1980). "A closed-form eqution for predicting the hydraulic conductivity of unsaturated soils". Soil Sci. Soc. Am. J., 44(5), 892-898.

\section{The following symbols are used in this paper}

$\begin{array}{lll}\theta & = & \text { Soil moisture content } \\ \mathrm{h} & = & \text { Soil water pressure }(\mathrm{L}) \\ \mathrm{K} & = & \text { Unsaturated Hydraulic Conductivity }\left(\mathrm{LT}^{-1}\right) \\ \alpha & = & \text { Parameter in VG model }\left(\mathrm{L}^{-1}\right) \\ \mathrm{n} & = & \text { Parameter in VG model } \\ \mathrm{h}_{\mathrm{d}} & = & \text { Parameter in BC model (air entry pressure) }(\mathrm{L}) ; \\ \lambda & = & \text { Parameter in BC model (Pore size distribution index) } \\ \mathrm{m} & = & 1-1 / \mathrm{n} \\ \theta_{\mathrm{r}} & = & \text { Residual water content } \\ \theta_{\mathrm{s}} & = & \text { Saturated water content } \\ \theta_{\mathrm{m}} & = & \text { apparent "irreducible" water content } \\ \mathrm{K}_{\mathrm{s}} & = & \text { Saturated hydraulic conductivity in VG model and BC model }\left(\mathrm{LT}^{-1}\right) ; \\ \sigma_{\mathrm{b}} & = & \text { Bulk density } \\ \mathrm{S} & = & \text { water saturation } \\ \mathrm{S}_{\mathrm{e}} & = & \text { effective saturation } \\ \mathrm{S}_{\mathrm{m}} & = & \text { irreducible water saturation }\left(\theta_{\mathrm{m}} / \theta_{\mathrm{s}}\right)\end{array}$

